\title{
Improvement in Hair Loss and Better Hair Quality with Vitamin Therapy in Monilethrix
}

\section{Rajesh Rajput}

Hair Transplant Surgeon, 201, A Wing, Gasper Enclave, Pali Market, Ambedkar Road, Bandra West, Mumbai, 400050 , India.

*Corresponding author: Rajesh Rajput, Hair Transplant Surgeon, 201, A Wing, Gasper Enclave, Pali Market, Ambedkar Road, Bandra west, Mumbai, 400 050, India, Tel: +91-22- 26415298; E-mail: drrajeshrajput@gmail.com

Received date: October 13, 2016; Accepted date: November 18, 2016; Published date: December 5, 2016

Copyright: (c) 2016 Rajput R. This is an open-access article distributed under the terms of the Creative Commons Attribution License, which permits unrestricted use, distribution, and reproduction in any medium, provided the original author and source are credited.

\begin{abstract}
Monilethrix or beaded results from a genetic abnormality of defective hair shaft formation. The altered genetics leads to improper, inefficient, incorporation of structural proteins, minerals during hair shaft formation resulting in weak, brittle hair. Other hair shaft disorders like pili torti, pili trianguli, trichorrhexis nodosa, trichorrhexis invaginata and pili annulati, rolled hair and circular hair are reported to be associated with vitamin, mineral, amino acid deficiencies. The nutritional etiology can be recognized as a common thread. Combined nutritional deficiencies can lead to occurrence of more than one hair shaft disorder in the same patient. Hair shaft disorders are also diagnostic of certain mineral deficiencies. Temporary benefit in hair shaft disorders has been reported with the use of minoxidil $2 \%$, acitretin, retinoids, $\mathrm{N}$-acetyl cysteine and iron supplementation. The genetic disorder may not be amiable to correction, however nutritional deficiencies or imbalance can be corrected to produce hair of better strength and better quality. We report improvement of hair shaft structure and reduced hair breakage in case of Monilethrix with use of vitamins, minerals, amino acids and suggest that nutritional correction can offer relief to patients with hair shaft disorders with the understanding that it will be a better hair care though not a cure. The program delivers wellness, good health as well as hair growth without use of any oral medication and without the fear of side effects.
\end{abstract}

Keywords: Fragile hair; Coarse hair; Hypotrichosis; Anisotrichosis; Trichoscopy

\section{Introduction}

Monilethrix is a disorder of beaded hair caused by genetic mutation with variable expression. The disorder leads to formation of thin, fragile hair, easily damaged by handling or friction. Monile means necklace (Latin) and thrix means hair (Greek) [1,2]. Hair shaft shows regular fusiform nodes and internodes formed at every $0.7-1 \mathrm{~mm}$ along the length of the hair [1]. Other hair shaft disorders are Pili torti, Pili trianguli, Trichorrhexis nodosa, Trichorrhexis invaginata and Pili annulati, rolled hair and circular hair. Temporary benefit in hair shaft disorders has been reported with minoxidil $2 \%$, acitretin, retinoids, Nacetyl cysteine and iron [2-4]. The altered genetics leads to improper, inefficient, incorporation of structural proteins, minerals for hair shaft formation. We report a case of monilethrix showing improvement in hair shaft formation within 4 months with low dose nutritional supplements and $2 \%$ minoxidil.

\section{Case Report}

A 22 year young female of non-consanguineous marriage presented with thinning of hair, slow growth, dry lustreless and coarse hair, broken hair falling all over, especially seen on the pillow every morning, excessive hair loss during combing and shampoo, since childhood as early as 2-3 years of age. Mother confirmed the hair to be normal at birth. Patient always felt several small nodules in the scalp, more over the occipital area. Family history confirmed that brother, sister, mother and family members from mother's side have the same problem with their hair though with varying severity [1].

\section{Clinical examination and trichoscopy}

Dull coarse fragile hair, looking like a short hair style, thinning over frontal, temporal and occipital areas. Hypotrichosis and very short broken hairs over occipital area up to the nape of the neck, here the hair was hardly a centimeter in length with several keratotic papules (Figure 1). Axillary hairs appeared sparse, short and fragile. Eyebrows, eyelashes were normal. Body hair was thin, nails were deformed showed koilonychia. Patient had no other skin lesions, or anomalies [1]. General and systemic examination was normal.

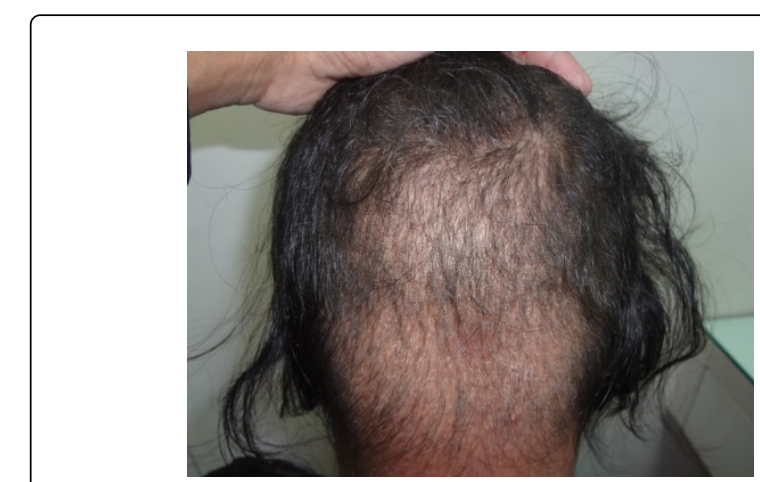

Figure 1: Occipital view monilethrix fragile hair and poor growth.

Trichoscopy showed thin curved hair with beaded appearance, regular fusiform, elliptical nodes along the shaft, with constrictions or internodes (Figure 2). 
Citation: Rajput R (2016) Improvement in Hair Loss and Better Hair Quality with Vitamin Therapy in Monilethrix. J Cosmo Trichol 2: 113. doi: $10.4172 / 2471-9323.1000113$

Page 2 of 5

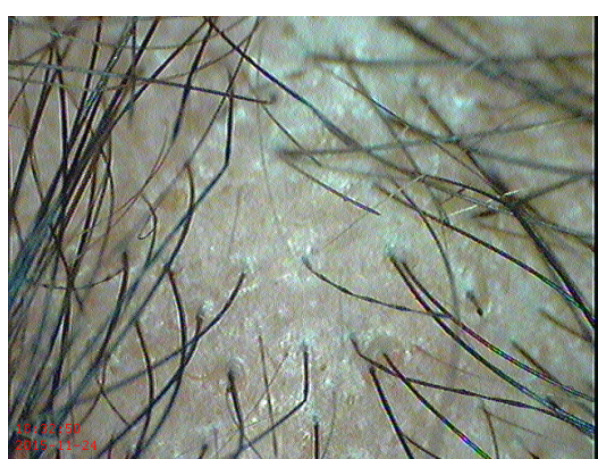

Figure 2: Beaded hair with adjacent hair broken at weak nodes.

Several hairs had hair breakage at these nodes which appear to be the weak spots (Figure 2). Absence of medulla at the site of the constrictions along the shaft is reported [2], but could not appreciate on routine trichoscopy. Several adjacent hairs were non beaded, normal in appearance but these too were fragile and broken (Figure 2) indicating poor hair shaft formation. There was variation in hair shaft diameter displaying anisotrichosis. Vellus hair and broken hair were found all over the scalp with occasional keratotic papules. Photographs were recorded in five standard views, frontal, right temporal, left temporal, vertex and occipital. Hair counts for density per square centimeter and hair caliber in microns was recorded. These evaluations were compared every two months (Figure 3).

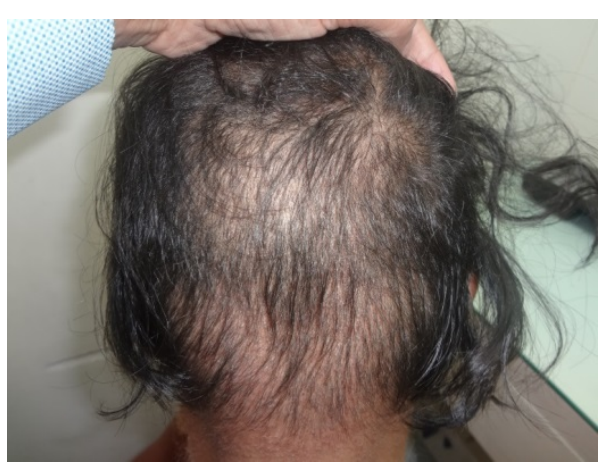

Figure 3: Occipital view monilethrix new hair growth retained with less breakage.

Patient was advised minoxidil $2 \%$ two times a day along with low dose, once in 3 days, cyclical vitamin therapy. The vitamins included, antioxidants, calcium, Vit D3, zinc, magnesium, on day one, iron, folic acid, Vitamin C, omega 3 fatty acids on day two, B-complex, biotin and amino acids on day three. These continued to repeat every 3 days, in a cycle. The therapy has been reported to show benefit in hair loss management [5-7].

\section{Results}

Within 2 months patient showed better hair growth (Figures 1,3 and Figures 4,5), improved hair caliber and appreciation of hair quality.

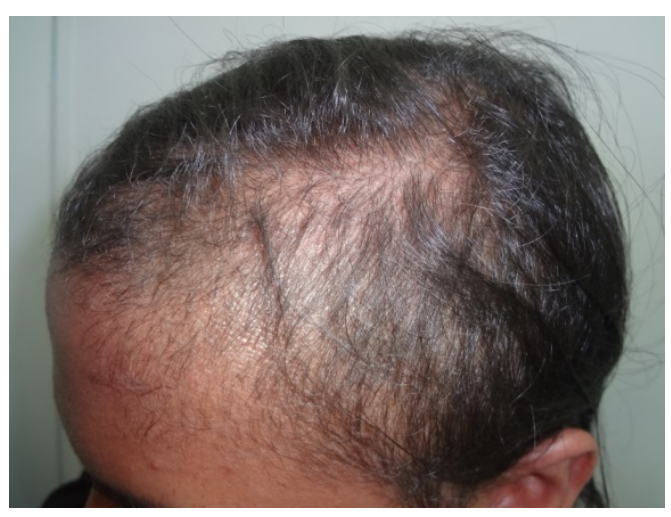

Figure 4: Right temporal view monilethrix fragile hair poor growth.

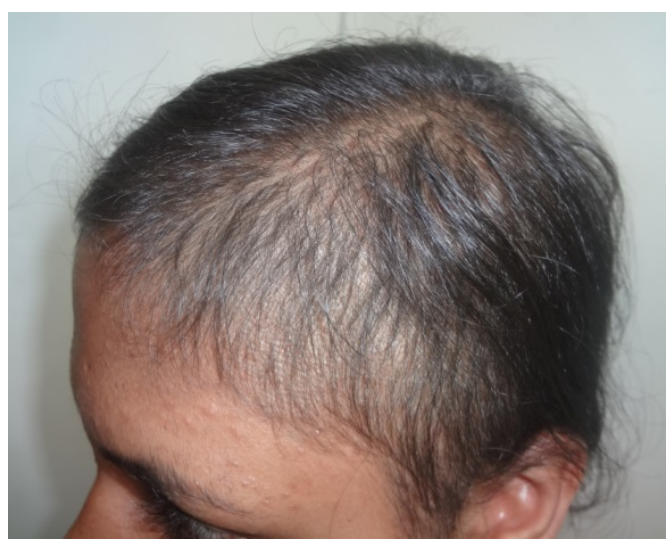

Figure 5: Right temporal view monilethrix new hair growth retained with less breakage.

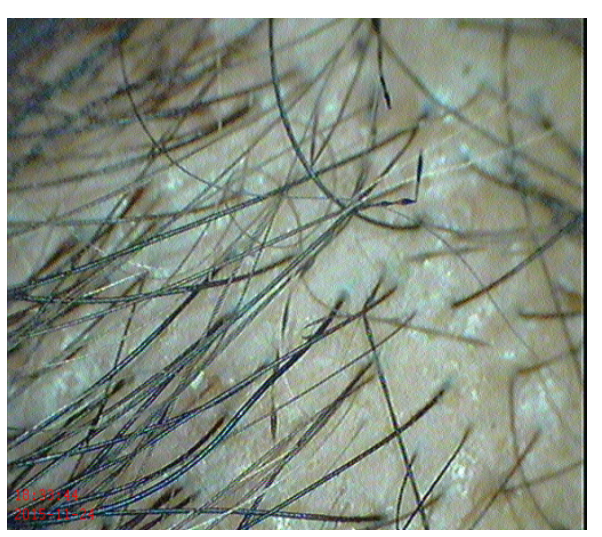

Figure 6: Fewer beaded hair shafts after 4 months of nutritional therapy.

Fragility and hair breakage were reported to be reduced, hair felt stronger. At the end of 4 months the hair caliber had improved by $18 \%$. Hair density had improved by $23 \%$. Number of vellus hair had reduced by $35 \%$. There was improvement in all the five areas, frontal, both 
temporal, vertex and occipital. Beaded hair could still be seen but many of the adjacent hair had normal non beaded shafts (Figure 6).

\section{Discussion}

Apart from beaded hair seen on trichoscopy surrounding non beaded hairs were also seen to be fragile and broken, indicating varied clinical presentations and various grades of hair shaft changes created by the same pathology. Hair loss and breakage could still occur without always manifesting all the criteria attributed to the clinical disorder. Koilonychia is commonly seen with monilethrix and often regarded as the hallmark of iron deficiency. However, scientific studies have indicated that koilonychia apart from just iron deficiency, also represents protein deficiency and metabolic imbalance, which may be due to hematological, cardiocvascular or endocrine causes [1-4,8-10]. The koilonychia associated with monilethrix could indicate multiple systemic etiology and associated nutritional deficiencies which may require correction.

\section{Studies in monilethrix and other hair shaft disorders}

Studies by various researchers support the use of low dose nutritional supplements in hair shaft disorders. Though hair shaft disorders have a genetic mutation, the effective mechanism may be through altered metabolism leading to altered hair shaft formation. Either way several research workers have reported benefit in hair shaft disorders from promotion of growth with $2 \%$ minoxidil and nutritional correction [11,12]. Based on reports that hair with Trichorrhexis nodosa and Pili torti have shown cysteine deficiency [3], Vikramkumar et al. treated monilethrix hair with $\mathrm{N}$-acetyl cysteine reported temporary improvement. Monilethrix has been treated with $2 \%$ minoxidil [8], oral acitretin, $\mathrm{N}$-acetylcysteine, retinoids and iron [1-4]. If we review other hair shaft disorders, these are all found to have benefited with nutritional correction.

Pili torti, twisted ribbon like hair, occurring in Menken's disease results from poor copper absorption [9]. The etiology suggests that there could be poor absorption of other nutrients as well. Mirmirani et al. reported a new insight on distortion of hair and shaft formation resulting from mitochondrial dysfunction, influenced by accumulation of reactive oxygen species, thus indicating possible benefit from use of antioxidants [12]. Pili torti has been reported to occur in anorexia [13], malnutrition, combined with ingestion of exaggerated amounts of yellow vegetables and excess vitamin supplements, causing a significant increase in levels of serum carotene, retinyl esters, retinol, and retinoic acid [13]. Thus there is a suggested link with excess vitamin A causing hair shaft disorders [13]. There is also a caution that antioxidants though useful should not be advocated in excess.

Pili trianguli recognized by many more names as pili canaliculi, uncombable hair or spun glass hair and Cheveux incoiffables is longitudinal grooving of the hair shaft, which appears triangular in cross section, looking like frizzy hair growing in all directions [14]. The condition many times corrects as the child grows, which may be said to happen because the nutritional levels improve when the child gets older?

Trichorrhexis nodosa may occur from genetic weakness, physical or chemical damage or hair abrasion [15]. Hair treatments, perming, straightening, bleaching, highlighting, brushing, blow drying, combing and brushing tangled hair [16-18]. It is also associated with argininosuccinic aciduria and hypothyroidism $[18,19]$. We know that patients having hair loss due to hypothyroidism have iodine and zinc deficiencies which respond to nutritional correction [20].

Trichorrhexis invaginata or Bamboo hair is caused by intermittent keratinizing defect of the hair cortex. Incomplete conversion of the sulfhydryl-SH group onto S-S disulfide bonds [21], leading to cortical softness and invagination of keratinized distal hair shaft into the softer proximal shaft. Appears like an intussusception, ball-and-socket hair shaft deformity. Hair is brittle, resulting in breakage and short hairs. The condition also occurs in ichthyosis linearis circumflexa and Netherton's syndrome which is a triad of ichthyosiform erythroderma (inflamed, red, scaly skin), short, brittle, lustreless hair and atopic diathesis (predisposition to allergy problems) [21-23]. Reports have mentioned low dose retinoid therapy is reported to benefit Trichorrhexis invaginata [22,23]. This hair shaft disorder too improves on nutritional correction with caution to use low dose or be careful to avoid excess use of retinoids [22].

Pili annulati is a genetic trait showing hair banded with alternate segments of light and dark color. Another type of banded hair is seen in malnutrition where it signifies periods of normal and restricted growth [24]. Pili annulati can occur with auto immune alopecia areata and thyroid disease [25]. Pili annulati is found to be disorder of protein metabolism due to dysfunction of cytoplasmic ribosomes affecting cortical keratin formation [26], which can therefore be expected to respond to supplementation of essential amino acids and nutritional correction.

Rolled hairs appear as irregular coils of hair along with keratin plugs and inflammation. Genetic factor is suspected but not proven. It is a disorder of follicular hyperkeratosis [27,28] associated with scurvy, ichthyosis, keratosis pilaris, xerosis, atopic dermatitis, palmoplantar keratoderma, neurodermatitis and corticosteroid therapy [27,28]. Treatment of the underlying condition is indicated, which most often translates into nutritional correction.

Circular hair appear as near perfect circular coils placed flat over the skin. The same circle can be traced to lay horizontally in the stratum corneum. Tightly coiled hair from below the epidermis can sometimes be extracted to roll out but it recoils back into the circular track. There is no inflammation, the hair shaft is thin, weak, unable to penetrate the stratum corneum, thus forming horizontal tracks [27-31]. Commonly seen in elderly, obese, hairy males over the thighs. This hair may be said to require strengthening of the hair shaft and better growth which is possible through nutritional support.

A review of the research on various hair shaft disorders points out to weak hair formation due to disruption of the metabolism and biology of hair shaft formation. The conclusion that hair shaft disorders are a variable expression of a common pathology is also indicated by reports of multiple accompanying defects seen in the same patient $[32,33]$. Hair shaft disorders are found associated with alopecia areata [34-36]. The detection of hair shaft disorders is regarded a diagnostic tool in neurological diseases, metabolic errors, malformations and conditions of mitochondrial dysfunction. Therefore we concluded that for our treatment plan, the use of antioxidants for scavenging free radicals to improve metabolic processes and provide additional nutrients which are the building blocks for formation of strong hair, combined with stimulation of hair growth, the approach was expected to show improvement in hair quality, reduced hair breakage and result in better hair growth. 


\section{Planned approach to nutritional therapy}

We understand that no individual nutrient can be held responsible for poor hair growth. A balance of nutrients is required instead of focusing attention on any single nutrient. The research workers who have reported that hair shaft disorder temporarily responded to $\mathrm{N}$ Acetylcysteine (3) or retinoids [3,21,22] have not realized the requirement other nutrients to be included in the treatment regimen. They have also overlooked long term use of the supplements in order to ensure continued relief. Use of supplements compensates the failure of metabolism and ensures proper hair shaft formation. It does not cure the genetic error. The use of nutritional supplements is a support or a care program, not a cure. Hence discontinuing the therapy leads to loss of the improvement achieved. Structure of the hair is made up of multiple minerals, amino acids and requires vitamins, coenzymes to ensure conduction of the metabolic processes which incorporate these building blocks into creation of new hair growth. Many reports from earlier workers indicated that low dose nutrients were effective in achieving some degree of correction or benefit in various hair shaft disorders [3]. Role of altered protein metabolism and reactive oxygen species in hair shaft disorders, has been investigated $[2,3]$.

Advantage of previous research workers lead us to create a comprehensive hair care program utilizing antioxidants and low dose nutritional supplements for hair growth, which would permit prolonged use without fear of hypervitaminosis and reduce the cost of the therapy. Minoxidil 2\% application of $1 \mathrm{ml}$ two times a day was used for stimulation of hair growth. Supplements were used in divided doses spread over 3 days, to repeat twice a week instead of being advised all seven days a week. Patient was advised Antioxidants, calcium, Vitamin D3, zinc, magnesium, on day one, iron, folic acid, Vit C, omega 3, fatty acids on day two, B-complex, biotin and amino acids on day three. These continued to repeat every 3 days, in the same cycle [5-7]. The therapy was referred to as Cyclical Vitamin Therapy. The present case of Monilethrix treated with this therapy and showed response beginning in 2 months and satisfactory improvement in 4 months.

Patient showed improved hair growth, reduced hair breakage, dull dry lifeless hair changed to healthy shiny hair, with better bounce and improved hair quality. At the end of 4 months the hair caliber had improved by $18 \%$. Hair density had improved by $23 \%$. Number of villus hair had reduced by $35 \%$. Subjective improvement was noticed by the patient within 2 months of commencing the therapy. This case report suggests that minoxidil $2 \%$ and well planned low dose nutritional support should be tried for benefit in hair shaft disorders.

\section{References}

1. Oliveira EF, Araripe AL (2015) Monilethrix: a typical case report with microscopic and dermatoscopic findings. An Bras Dermatol 90: 126-127.

2. Jain N, Khopkar U (2010) Monilethrix in pattern of distribution in siblings: Diagnosis by Trichoscopy. Int J Trichol 2: 56-59.

3. Vikramkumar AG, Kuruvila S, Ganguly S (2013) Monilethrix: A Rare Hereditary Condition. Indian J Dermatol 58: 243.

4. Karaman GC, Sendur N, Basar H, Bozkurt Savk E (2001) Localized monilethrix with improvement after treatment of iron deficiency anaemia. J Eur Acad Dermatol Venereol. 15: 362-364.

5. Rajput RJ (2008) Cyclical Medicine for hair loss management and improved results in hair transplantation. Hair Transplant Forum International 18: 208-210.

6. Rajput RJ (2010) Controversy: is there a role for adjuvants in the management of male pattern hair loss? J Cutan Aesthet Surg 3: 82-86.
7. Rajput R (2015) Understanding Hair Loss due to Air Pollution and the Approach to Management. Hair Ther Transplant 5: 133.

8. Rossi A, Iorio A, Scali E, Fortuna MC, Mari E, et al.(2011) Monilethrix treated with minoxidil. Int J Immunopathol Pharmacol 24: 239-242.

9. Moore CM, Howell RR (1985) Ectodermal manifestations in Menkes disease. Clinical Genetics 28: 532-540.

10. Singal A, Arora R (2015) Nail as a window of systemic diseases. Indian Dermatol Online J 6: 67-74.

11. Leung AK (1985) The many causes of koilonychia. Hosp Pract (Off Ed) 20: 29.

12. Mirmirani P, Samimi SS, Mostow E (2009) Pili torti: Clinical findings, associated disorders, and new insights into mechanisms of hair twisting. Cutis 84: 143-147.

13. Lurie R, Danziger Y, Kaplan Y, Sulkes J, Abramson E, et al.(1996) Acquired pili torti--a structural hair shaft defect in anorexia nervosa. Cutis 57: 151-156.

14. Itin PH, Buhler U, Buchner SA, Guggenheim R (1993) Pili trianguli et canaliculi: a distinctive hair shaft defect leading to uncombable hair. Dermatology187: 296-298.

15. Ogunbiyi A, Ogun O, Enechukwu N (2014) Recurrent Hair Loss Resulting from Generalized Proximal Trichorrhexis Nodosa in a Nigerian Female. Int J Trichology 6: 83-84.

16. Mirmirani P (2010) Ceramic flat irons: Improper use leading to acquired trichorrhexis nodosa. J Am Acad Dermatol 62: 145-147.

17. Martin AM, Sugathan P (2011) Localised Acquired Trichorrhexis Nodosa of the Scalp Hair Induced by a Specific Comb and Combing Habit - A Report of Three Cases. Int J Trichology 3: 34-37.

18. Papa CM, Mills OH, Hanshaw W (1972) Seasonal trichorrhexis nodosa Role of cumulative damage in frayed hair. Arch Dermatol 106: 888-892.

19. Lurie R, Hodak E, Ginzburg A, David M (1996) Trichorrhexis nodosa: A manifestation of hypothyroidism. Cutis 57: 358-359.

20. Betsy A, Binitha M, Sarita S (2013) Zinc Deficiency Associated with Hypothyroidism: An Overlooked Cause of Severe Alopecia. Int J Trichology 5: 40-42.

21. Ito $\mathrm{M}$, Ito $\mathrm{K}$, Hashimoto $\mathrm{K}$ (1984) Pathogenesis in trichorrhexis invaginata (bamboo hair). J Invest Dermatol 83: 1-6.

22. Hartschuh W, Hausser I, Petzoldt D (1989) [Successful retinoid therapy of Netherton syndrome]. Hautarzt 40: 430-433.

23. Lazaridou E, Apalla Z, Patsatsi A, Trigoni A, Ioannides D (2009) Netherton's syndrome: successful treatment with isotretinoin. J Eur Acad Dermatol Venereol 23: 210-212.

24. Murugusundram S (2009) Spangled Hair in Siblings. Int J Trichology 1: 35-36.

25. Castelli E, Fiorella S, Caputo V (2012) Pili Annulati Coincident with Alopecia Areata, Autoimmune Thyroid Disease, and Primary IgA Deficiency: Case Report and Considerations on the Literature. Case Rep Dermatol 4: 250-255.

26. Ito M, Hashimoto K, Sakamoto F, Sato Y, Voorhees JJ (1988) Pathogenesis of pili annulati. Arch Dermatol Res 280: 308-318.

27. Nair PA, Kota RS, Gandhi S, Singhal RR (2016) A rare association of pili multigemini and rolled hairs in a young female. Int J Trichol 8: 29-31.

28. Contreras RJ, Duran MC, Tamayo SL, Orozco CL, Ruiz MR (2000) Circle hairs: A clinical curiosity. J Eur Acad Dermatol Venereol 14: 495-497.

29. Argueta EE, Tschen JA (2014) Hair with an irregular shape. Cutis 94: E4E5.

30. Smith JB, Hogan DJ (1996) Circle hairs are not rolled hairs. J Am Acad Dermatol 35: 634-635.

31. Lacarrubba F, Misciali C, Gibilisco R, Micali G (2013) Circle hairs: Clinical, trichoscopic and histopathologic findings. Int J Trichology 5: 211-213.

32. Leider M (1950) Multiple simultaneous anomalies of the hair; report of a case exhibiting trichorrhexis nodosa, pili annulati and trichostasis spinulosa. AMA Arch Derm Syphilol 62: 510-514. 
Citation: Rajput R (2016) Improvement in Hair Loss and Better Hair Quality with Vitamin Therapy in Monilethrix. J Cosmo Trichol 2: 113. doi: 10.4172/2471-9323.1000113

Page 5 of 5

33. Moffitt DL, Lear JT, de Berker DA, Peachey RD (1998) Pili annulati coincident with alopecia areata. Pediatr Dermatol 15: 271-273.

34. Coulter DL, Beals TF, Allen RJ (1982) Neurotrichosis: hair-shaft abnormalities associated with neurological diseases. Dev Med Child Neurol 24: 634-644.
35. Silengo M, Valenzise M, Sorasio L, Ferrero GB (2002) Hair as a diagnostic tool in dysmorphology. Clin Genet 62: 270-272.

36. Silengo M, Valenzise M, Spada M, Ferrero GB, Ferraris S, et al.(2003) Hair anomalies as a sign of mitochondrial disease. Eur J Pediatr 162: 459-461. 